\title{
On Approach of Analysis of Oscillations of a Multilayer Structures
}

\author{
Pankratov EL ${ }^{1,2 *}$ \\ ${ }^{1}$ Nizhny Novgorod State University, 23 Gagarin avenue, Nizhny Novgorod, 603950, Russia \\ ${ }^{2}$ Nizhny Novgorod State Technical University, 24 Minin Street, Nizhny Novgorod, 603950, Russia
}

Submission: June 23, 2020; Published: January 15, 2021

*Corresponding author: Pankratov EL, Nizhny Novgorod State University, 23 Gagarin avenue, Nizhny Novgorod, 603950, Russia

\section{Abstract}

In this paper we analyzed sound influence on a multilayer building structures with increasing sound insulation on the example of oscillations of a multilayer plate. An analytical approach for analyzing the data of oscillations has been introduced.

Keywords: Multilayer building structures; Increasing sound insulation; Analytical approach for modelling

\section{Introduction}

High rates of development of construction equipment create the necessary prereq-uisites for the design and construction of buildings and other structures of elements that have significant strength and stability with low weight and small thickness [15]. At the same time, the development of technology leads to the emergence of more powerful machines and to increasing number of vehicles, which leads to increasing of noise in populated areas, civil and industrial buildings. Acoustic improvement of premises becomes an actual problem of each design and construction of each building [6-9]. Framework solving this problem, the problem of the sound-insulating ability of the enclosing and supporting structures is first of all solved. To solve the problem, it is necessary to analyze the sound effect on the structure. Framework the paper, an analysis of this effect has been done, considering the possible multilayered structure. We will analyze this effect using the example of transverse oscillations of a multilayer plate (structure) due to the action of a plane sound wave perpendicular to the interface between the layers of the plate.

\section{Method of solution}

The oscillation of the plate is determined by solving the following wave equation

$$
\frac{\partial_{2} \mathrm{u}(\mathrm{x}, \mathrm{y}, \mathrm{z}, \mathrm{t})}{\partial \tilde{n}^{2} 1-\tilde{n}}=\frac{\mathrm{E}}{(\mathrm{x})} \frac{\partial^{2} \mathrm{u}(\mathrm{x}, \mathrm{y}, \mathrm{z}, \mathrm{t})}{\partial \tilde{n}^{2} 1-\tilde{n}}+\frac{\mathrm{E}}{(\mathrm{y})} \frac{\partial^{2} \mathrm{u}(\mathrm{x}, \mathrm{y}, \mathrm{z}, \mathrm{t})}{\partial^{2}}+\mathrm{F}(\mathrm{x}, \mathrm{y}, \mathrm{z}, \mathrm{t}),
$$

where Eis the modulus of elasticity; $\tilde{n}$ is the density of the plate materials; $\sigma$ is the Poisson ratio, $\mathrm{u}(\mathrm{x}, \mathrm{y}, \mathrm{z}, \mathrm{t})$ is the displacement of the points of the plate when it oscillates; $\mathrm{F}(\mathrm{x}, \mathrm{y}, \mathrm{z}, \mathrm{t})$ is the external impact (impact, sound wave, etc.); $L_{x}, L_{y}$ and $L_{z}$ are the dimensions of the plate in the directions indicated in the indices; $x, y$ and $z$ are spatial coordinates; $t$ is time. Let us consider the case when the edges of the plate are rigidly fixed and there is no effect on it at the time of the beginning of its consideration. Then the boundary and initial conditions for equation (1) could be written in the following form

$$
\left.\frac{\partial \mathrm{u}(\mathrm{x}, \mathrm{y}, \mathrm{z}, \mathrm{t})}{\partial x}\right|_{x=0}=0,\left.\frac{\partial \mathrm{u}(\mathrm{x}, \mathrm{y}, \mathrm{z}, \mathrm{t})}{\partial x}\right|_{x=L_{x}}=0,\left.\frac{\partial \mathrm{u}(\mathrm{x}, \mathrm{y}, \mathrm{z}, \mathrm{t})}{\partial y}\right|_{\mathrm{y}=0}=0,\left.\frac{\partial \mathrm{u}(\mathrm{x}, \mathrm{y}, \mathrm{z}, \mathrm{t})}{\partial y}\right|_{x=L_{y}}=0, \mathrm{u}(x, y, z, 0)=0 .
$$

Now we solve the Eq.(1) using the method of averaging functional corrections [10]. In the framework of this method, in order to obtain the first approximation of the desired function $\mathrm{u}(\mathrm{x}, \mathrm{y}, \mathrm{z}, \mathrm{t})$, replace it with the unknown average value $\alpha_{1}$ in the right-hand side of the Eq.(1). Then the equation for the first approximation of the function $\mathrm{u}(\mathrm{x}, \mathrm{y}, \mathrm{z}, \mathrm{t})$ takes the form

$$
\frac{\partial^{2} u_{1}(x, y, z, t)}{\partial t^{2}}=F(x, y, z, t)
$$

The solution of Eq. (3) is represented in the following form

$$
\mathrm{u}_{1}(\mathrm{x}, \mathrm{y}, \mathrm{z}, \mathrm{t})=\int_{0}^{t}(t-T) \mathrm{F}(x, y, z, T) .
$$

The average value of the function $\mathrm{u}(\mathrm{x}, \mathrm{y}, \mathrm{z}, \mathrm{t})$ is determined using the standard relation

$$
\alpha_{1}=\frac{1}{L_{x} L_{y} L_{z} \Theta_{0000}} \int^{\Theta} \int L^{L_{x}} \int^{L_{y}} \int^{L_{z}} \mathrm{u}_{1}(x, y, z, t) d z d y d z d t .
$$

where $\Theta$ is the duration of observation of the oscillation of the 


\section{Civil Engineering Research Journal}

considered plate. Substitution of the relation (3a) into (4) leads to the following result

$$
\alpha_{1}=-\frac{1}{2 L_{x} L_{y} L_{z} \Theta_{0000}} \int^{\Theta} \int^{L_{x}} \int^{L_{y}} \int^{L_{z}} \mathrm{t}^{2} \mathrm{~F}(x, y, z, T) d z d y d z d t .
$$

The second-order approximation of the function $\mathrm{u}(\mathrm{x}, \mathrm{y}, \mathrm{z}, \mathrm{t})$ is determined by replacing it in the right-hand side of the Eq. (1) by the sum of the approximation of the previous order and the mean value of the desired approximation $\alpha_{2}$, i.e. by the amount $\alpha_{2}+\mathrm{u}_{1}(\mathrm{x}, \mathrm{y}, \mathrm{z}, \mathrm{t})$. Then the equation for the second approximation of the function $\mathrm{u}(\mathrm{x}, \mathrm{y}, \mathrm{z}, \mathrm{t})$ takes the form

$$
\frac{\partial^{2} \mathrm{u}_{2}(\mathrm{x}, \mathrm{y}, \mathrm{z}, \mathrm{t})}{\partial \tilde{\mathrm{n}}^{2} 1-\tilde{\mathrm{n}}}=\frac{\mathrm{E}}{(\quad)} \frac{\partial^{2} \mathrm{u}_{1}(\mathrm{x}, \mathrm{y}, \mathrm{z}, \mathrm{t})}{\partial \tilde{\tilde{n}}^{2} 1-\tilde{\mathrm{n}}}+\frac{\mathrm{E}}{(\quad)} \frac{\partial^{2} \mathrm{u}_{1}(\mathrm{x}, \mathrm{y}, \mathrm{z}, \mathrm{t})}{\partial y^{2}}+\mathrm{F}(x, y, z, t)
$$

Solution of the Eq. (5) could be written as

$$
\mathrm{u}_{2}(\mathrm{x}, \mathrm{y}, \mathrm{z}, \mathrm{t})=\frac{\mathrm{E}}{\tilde{\mathrm{n}}(1-\tilde{\mathrm{n}})} \int_{0}^{t}(t-\tau) \frac{\partial^{2} \mathrm{u}_{1}(\mathrm{x}, \mathrm{y}, \mathrm{z}, \tau)}{\partial x^{2}} d \tau+\frac{\mathrm{E}}{\tilde{\mathrm{n}}(1-\tilde{\mathrm{n}})} \int_{0}^{t}(t-\tau) \frac{\partial^{2} \mathrm{u}_{1}(\mathrm{x}, \mathrm{y}, \mathrm{z}, \tau)}{\partial y^{2}} d \tau+\int_{0}^{t}(t-\tau) F(\mathrm{x}, \mathrm{y}, \mathrm{z}, \tau) d \tau .
$$

The average value $\alpha_{2}$ of the second-order approximation of the function $\mathrm{u}(\mathrm{x}, \mathrm{y}, \mathrm{z}, \mathrm{t})$ is determined using the standard relation [10]

$$
\alpha_{n}=\frac{1}{L_{x} L_{y} L_{z} \Theta_{0000}} \int_{0}^{\Theta} \int_{0}^{L_{x}} \int_{0}^{L_{y}} \int_{0}^{L_{z}}\left[\mathrm{u}_{n}(x, y, z, t)-\mathrm{u}_{n-1}(x, y, z, t)\right] d z d y d z d t,
$$

where $n$ is the order of the required approximation. Substitution of relations (3a) and (5a) into (6) leads to the following result

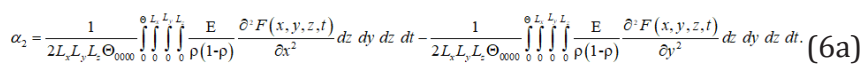

An analysis of the spatiotemporal distribution of the displacement of the plate points during its oscillation has been done analytically framework the second order approximation by the method of averaging the functional corrections. The approximation is usually enough for qualitative analysis and obtaining some quantitative results. The results of the analytical calculations were verified by comparing them with the numerical results.

\section{Discussion}

In this section, we will analyze the space-time distribution of the displacement of the points of the plate when it vibrates under the action of a plane wave $F(x, y, z, t)=A \cdot \exp \left(k_{z} z-\omega t\right)$, where $\mathrm{A}$ is the amplitude of the wave, $k_{z}$ is the projection of the wave number on the $\mathrm{Oz}$ axis, and $\mathrm{w}$ is the wave frequency. Figure 1 shows the qualitative spatial distribution of the displacement of the points of the plate as a function of the coordinates $\mathrm{x}$ and $\mathrm{y}$ at a fixed time. Figure 2 shows the qualitative spatiotemporal distribution of the displacement of the plate points as a function of the coordinate $\mathrm{z}$ and time $\mathrm{t}$ for fixed values of the $\mathrm{x}$ and $\mathrm{y}$ coordinates.

Figure 1: The qualitative spatial distribution of the displacement of the points of the plate as a function of the coordinates $x$ and $y$ at a fixed time.
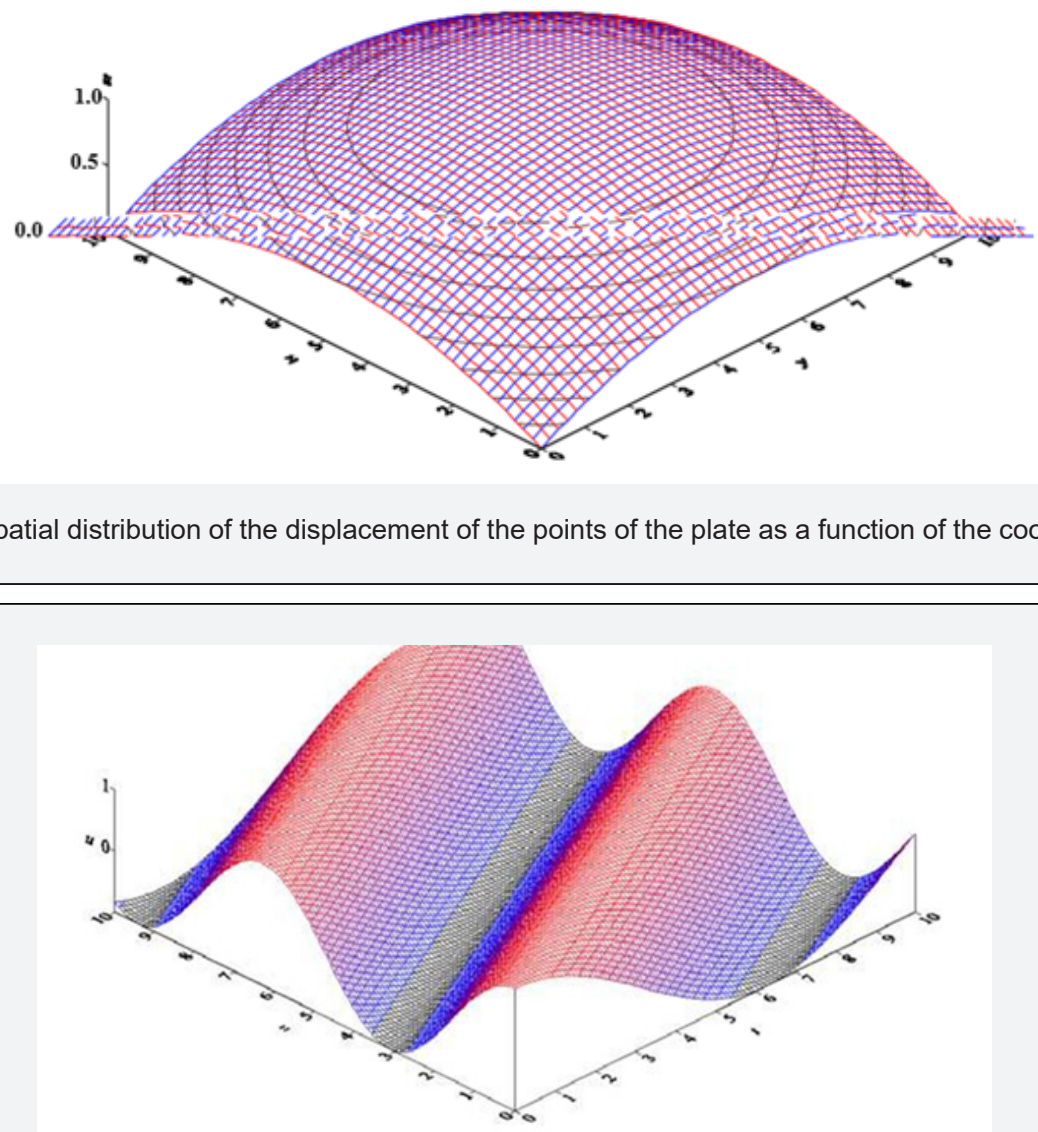

Figure 2: The qualitative space-time distribution of the displacement of the plate points as a function of the coordinate $\mathrm{z}$ and time $\mathrm{t}$ for fixed values of the coordinates $x$ and $y$. 


\section{Civil Engineering Research Journal}

\section{Conclusion}

In this paper, we propose an analytical approach for analyzing plate vibrations un-der the influence of external action. As an example of such an impact, sound impact is possible. The proposed analytical approach allows us to consider the multilayeredness of the plate under consideration.

\section{References}

1. Long L, Kang H, Mo R. KSCE Journal of Civil Engineering. 21(1): 178183

2. Xue H, Jian Zhang S. KSCE Journal of Civil Engineering. 21(5): 16061613.

3. Pisal AY, Jangid RS International Journal of Advanced Structural Engineering. 8(2): 213-227.
4. Zhang C, Zayed T, Hijazi W, Alkass S Open Journal of Civil Engineering 6(3): 442-461.

5. Gong Z, Zeng B, Han W, Xue S Open Journal of Civil Engineering. 7(2): 303-310.

6. Broujerdian Email V, Kaveh A, Rahmani M Asian Journal of Civil Engineering. 19(6): 693-701.

7. Nayak AN, Satpathy L, Prasant K International Journal of Advanced Structural Engineering 10(2): 153-167.

8. Long NV, Quoc TH, Tu TM 8(4); 391-399.

9. Tran MT, Nguyen VL, Trinh AT International Journal of Advanced Structural Engineering. 9(2): 153-164.

10. (1955) Yu D Sokolov. Applied Mechanics. 1(1): 23.

\section{Your next submission with Juniper Publishers} will reach you the below assets

- Quality Editorial service

- Swift Peer Review

- Reprints availability

- E-prints Service

- Manuscript Podcast for convenient understanding

- Global attainment for your research

- Manuscript accessibility in different formats

(Pdf, E-pub, Full Text, Audio)

- Unceasing customer service

Track the below URL for one-step submission https://juniperpublishers.com/online-submission.php 